\title{
Assessing Browse Trend At The Landscape Level Part 1: Preliminary Steps And Field Survey
}

\author{
By Richard B. Keigley, Michael R. Frisina, and Craig W. Fager
}

$\mathrm{W}$ Oody plants are an important component of rangeland habitat, providing food and shelter for animals that range in size from moose to warblers to insects. Because of this importance, land managers are paying increased attention to browse trends. In this two-part article, we describe how browse trend is assessed at the Mt. Haggin Wildlife Management Area in southwestern Montana.

Located south of Anaconda, Montana (Fig. 1), winters are extremely cold and windy at the Mount Haggin Wildlife Management Area. The annual precipitation is about 20 inches, much of which occurs as snow.

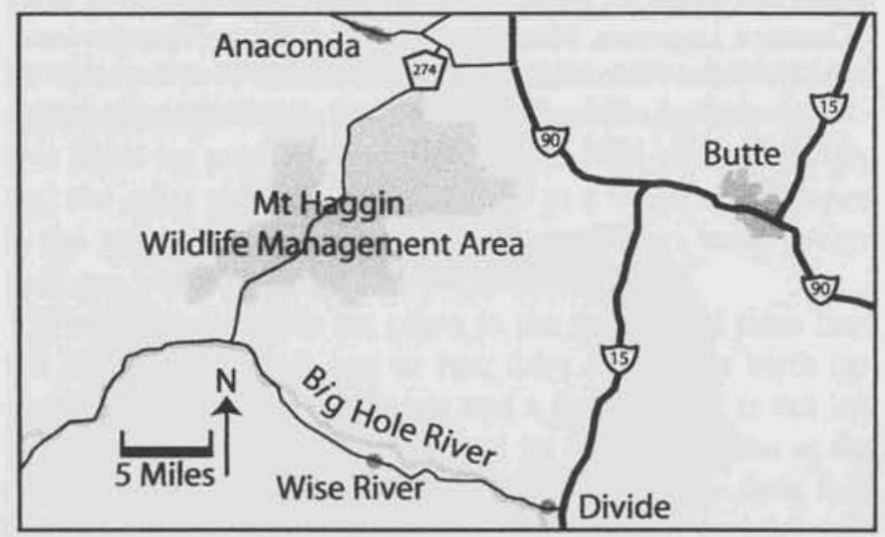

Fig. 1. Map of study area.

There are resident and transient ungulate populations. Moose is the only ungulate species present in all months. Elk, mule deer, and pronghorn antelope are present much of the year, but cannot contend with the deep snow cover that exists during mid-winter. Whitetail deer and cattle are present during the warm season. Cattle are managed under a three-pasture rest-rotation grazing system.

During the fall, a significant transient moose population is present. As snow cover deepens in the Pintler Mountains to the west, moose migrate from those mountains and stage in the area before migrating to lower elevation winter range in the Big Hole Valley. Over the past three decades, the moose population has increased. Censuses by Montana Fish, Wildlife \& Parks in the 1970 s reported an average of

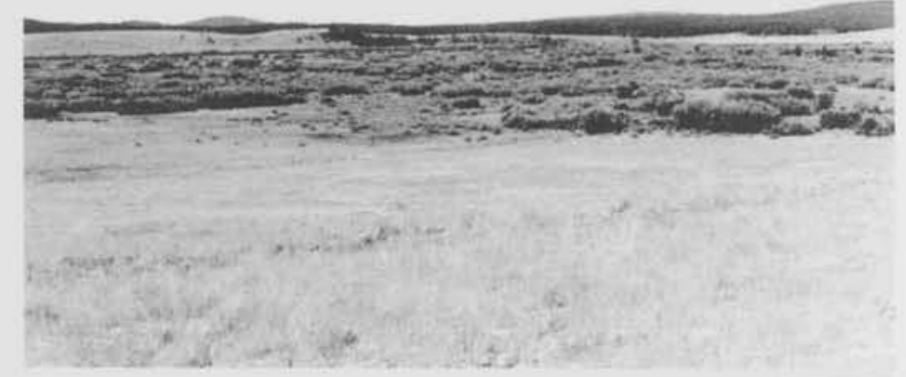

Fig. 2. Willow community provides critical habitat for wildlife.

9 animals; in 1980s, an average of 19 animals was reported; in the 1990s, an average of 39 was reported.

Willows present in the study area include Geyer, Drummond, Booth, planeleaf, Scouler, and Wolfs willow (Fig. 2). The riparian species are found in two general kinds of valley bottoms. At the lower end of drainages, the valleys tend to be wide and flat-bottomed, and locally bordered by glacial moraines. Within some of the flat-valleybottom areas, willow communities are confined to the corridor immediately adjacent to relic or current stream courses. At other locations, ponding caused by beaver dams, has allowed willow communities to spread across a broad area. At the upper end of the drainage, willows are confined within relatively narrow, $v$-shaped valleys. In the upper drainages, conifers often are present within the willow community.

Willows are currently heavily browsed (Fig. 3), but there is evidence that browsing pressure was lower in the past. Heavily-browsed 14-inch-tall plants grow in close proximity to 16-foot-tall plants, the tallest stems of which are unbrowsed (Fig. 4). The 16-foot-tall stems are older than the 14-inch-tall stems, and apparently grew through the browse zone when browsing pressure was lower than its current level. An increase in browsing pressure would be consistent with the increase in the moose population that occurred over the past 3 decades.

Our trend assessment involved five steps. Steps 1 through 3 were preliminary to the actual assessment of trend. Actual trend assessment occurred during steps 4 and 5 . 


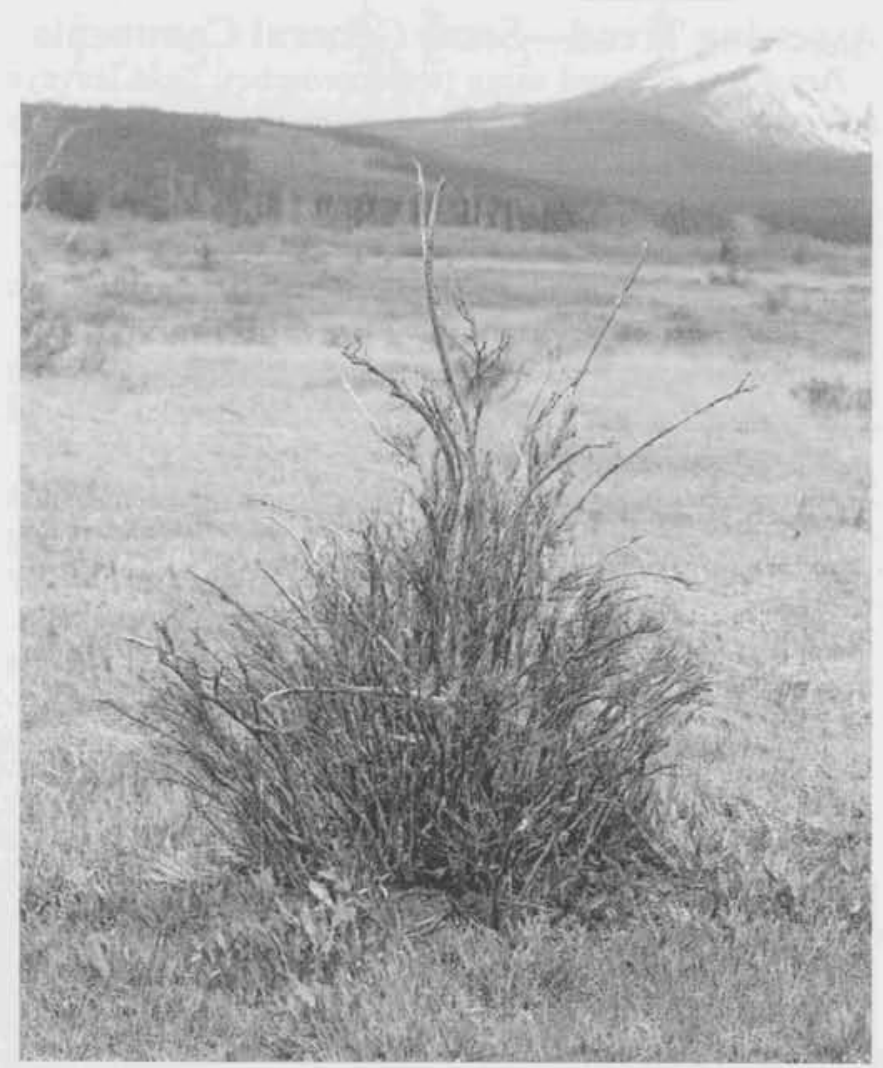

Fig. 3. Heavy browsing produces clusters of twigs at the ends of stems. A substantial portion of this shrub is dead.

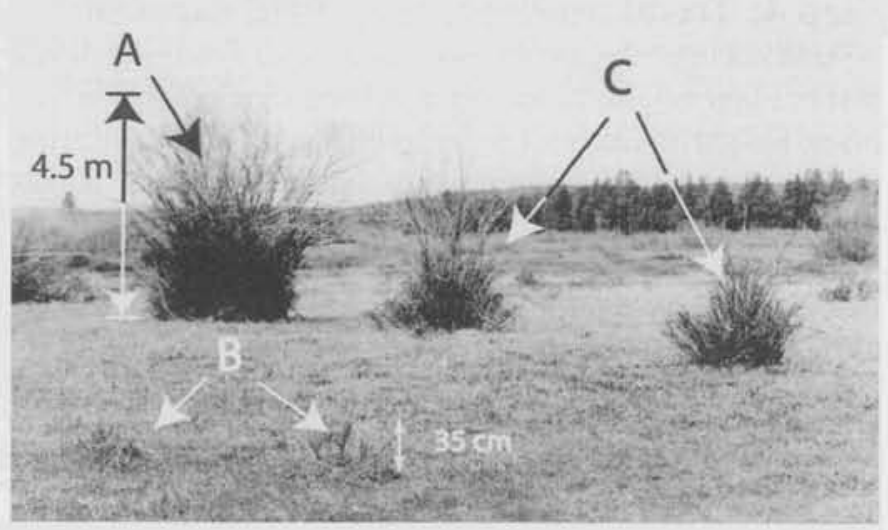

Fig. 4. A qualitative history of browsing can be interpreted by observing the relationship between plant height and plant age. In this case, an increase in browsing pressure has prevented young willows from attaining full stature.

\section{Step 1: Identify relevant management objectives}

The management of the browse resource was linked to area-wide management objectives. Two such objectives were deemed especially important. First, the area was purchased to provide winter range for big game. To serve as winter range, browse plants must be available for ungulate use under snow cover that ranges from negligible early in
Common and scientific names of species.

\section{Wild Ungulates}

\begin{tabular}{ll}
$\begin{array}{l}\text { moose } \\
\text { American pronghorn antelope }\end{array}$ & $\begin{array}{l}\text { Alces alces } \\
\text { Rocky Mountain elk }\end{array}$ \\
$\begin{array}{l}\text { Rocky Mountain mule deer } \\
\text { Whitetail deer }\end{array}$ & Cervis elaphus \\
& Odocoileus hemion \\
dogwood & O. virginianus \\
spruce & Plants \\
Booth willow & Cornus stolinifera \\
Drummond willow & Picea engelmannii \\
Geyer willow & Salix boothi \\
Planeleaf willow & S. drummondi \\
Scouler willow & S. geyeriana \\
Wolfs & S. planifolia \\
\hline
\end{tabular}

the winter season, to snow that lies more than 3- to 4-feet deep in mid-winter.

In addition, Montana Fish, Wildlife and Parks is committed to providing habitat for a variety of game and nongame wildlife. For example, Mt. Haggin Wildlife Management Area provides nesting habitat for sandhill cranes and neotropical migrants. Accomplishing these management objectives requires the presence of appropriately-sized woody plants.

At Mt. Haggin, willows range in height from very small, young plants, to older plants more than 16-feet tall. The preservation of this diversity in plant heights is essential to meeting the management objectives. Formally stated, the management objective is: Plants of diverse heights will be present, ranging to the full height potential as determined by local environmental conditions.

Full-statured plant stems (say those that grew to 16-feet tall) have a finite lifespan. If full-statured stems are to persist in a community, young stems must grow to full stature to replace those that die of old age. Heavy browsing can prevent young stems from growing through the browse zone. Continued long enough, heavy browsing can lead to the elimination of entire browse plant communities.

To maintain a plant community of varied heights, browsing must be light enough to allow young stems to grow through the browse zone and attain full stature. We used three methods to examine the fate of stems as they attempted to grow through the browse zone (architecture, stem height, and growth rate). Because full-statured stems are relatively long-lived, it is not necessary that all young stems grow to full stature- just some. Thus we look for evidence that browsing has prevented all young stems from growing tall.

\section{Step 2: Indicator species}

We focused on a single indicator species. That species should have two characteristics. First, it should be among 
those preferred by ungulates. A highly-preferred species (such as dogwood) is a more sensitive indicator of browse impacts than less-preferred species (such as spruce). Second, the indicator plants should be widely distributed across the managed area. From this distribution, managers can determine how browsing level varies across the landscape. We selected Geyer willow as the indicator species.

We assume that the fate of other browse species is indicated by the trend of Geyer willow. If Geyer willow is in decline, the decline of more-highly preferred species would already have occurred. As the amount of available Geyer willow diminishes, less-highly preferred browse species will begin to decline.

\section{Step 3: Delineating the distribution of the in- dicator species}

We prepared a map on which we estimated the total distribution of Geyer willow in the study area (Fig. 5). We

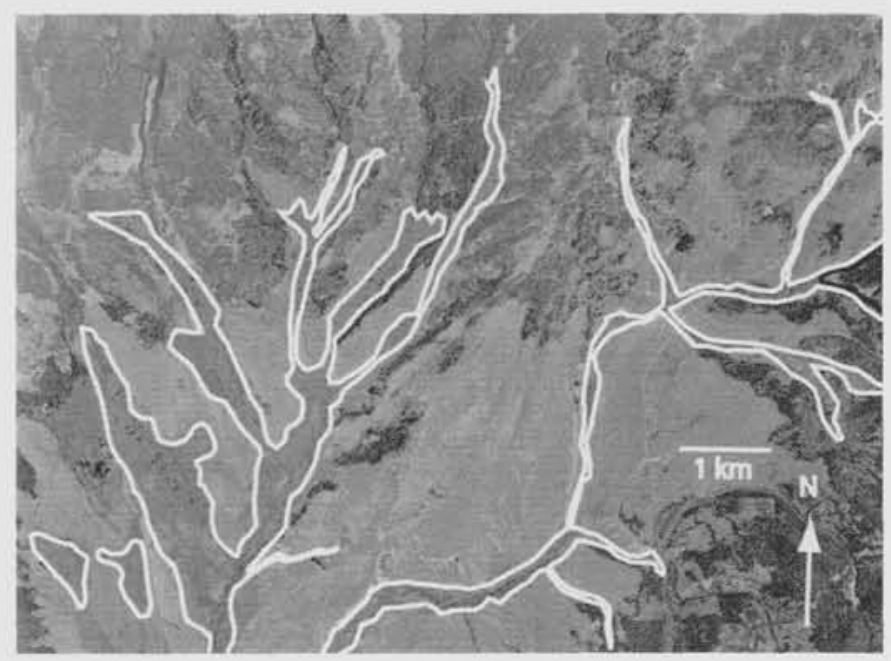

Fig. 5. Map showing distribution of Geyer willow. This map served as the basis for selecting areas for surveying and monitoring.

used the map to prioritize the subsequent steps of field surveying and monitoring. The map was based on a combination of site visits and by examining willow canopy cover on 1:12,000 aerial photographs. From site visits, we determined that Geyer willow extended across the full elevation range included in the study area. This distribution implied that, if any riparian willows were present in an area, Geyer willow plants would likely be included.

Because the map was to be used primarily for prioritizing future work, it was not necessary that the willow community boundaries be precisely drawn. In our case, high quality aerial photographs made the job relatively simple. This step could also be accomplished using images downloaded from the Internet or by delineating the approximate community boundaries on a topographic map.

\section{Assessing Trend-Some General Comments}

Trend was assessed using two approaches: field surveys and monitoring. During surveys, emphasis was placed on rapidly covering a broad geographic area. During monitoring, more-detailed data were collected from fixed locations; those same locations will be resampled periodically.

In the course of assessing trend, three different questions were addressed:

1. In recent years, have plants been able to grow through the browse zone? (This question is addressed in field surveys by examination of plant architectures.)

2. Over the long term, are plants growing taller? (This question is addressed during monitoring by comparing the height of live stems to the height of stems killed by browsing.)

3. Do plant stems grow fast enough to grow out of ungulate reach before they die? (This question was addressed during monitoring by determining stem lifespan and by measurement of growth rate.)

The data collected during surveys and monitoring complement one another; managers can emphasize one type of data over another to suit their needs. If it is most important to determine how browsing level might vary across the landscape, the manager can emphasize the survey component. Alternatively, managers wishing to track short-term changes in browsing impacts can do so with the type of data collected during monitoring.

\section{Step 4: Trend assessment by field surveys}

Field surveys document two aspects: a) browsing level, and b) plant height. Browsing level is an indicator of trend. Plant height indicates the availability of browse during winter. And if the community is in decline, plant height provides a rough indication of persistence; tall willow plants, with some stems out of ungulate reach, appear to live longer than shorter willows in which all terminal leaders are heavily browsed.

Below, we describe two field surveys, one conducted on a segment of Sullivan Creek, the other on a segment of Deep Creek. Both areas contain willows that range in height from very short, young plants (e.g., 8 inches) to older plants that are more than 16-feet tall.

Browsing level. Two levels of browsing are distinguished: a) intense, and b) light-to-moderate. In Keigley and Frisina (1998) we present specific rules for determining if a stem is intensely browsed. Intense browsing occurs when a complete annual segment is killed; current-year-growth develops from a segment older than the previous-year's-growth. Under light-to-moderate browsing, current-year-growth consistently develops from the previous-year's-growth. These rules apply at the stem level.

At the whole-plant level, browsing level affects plant architecture (growth form). We have identified four architec- 


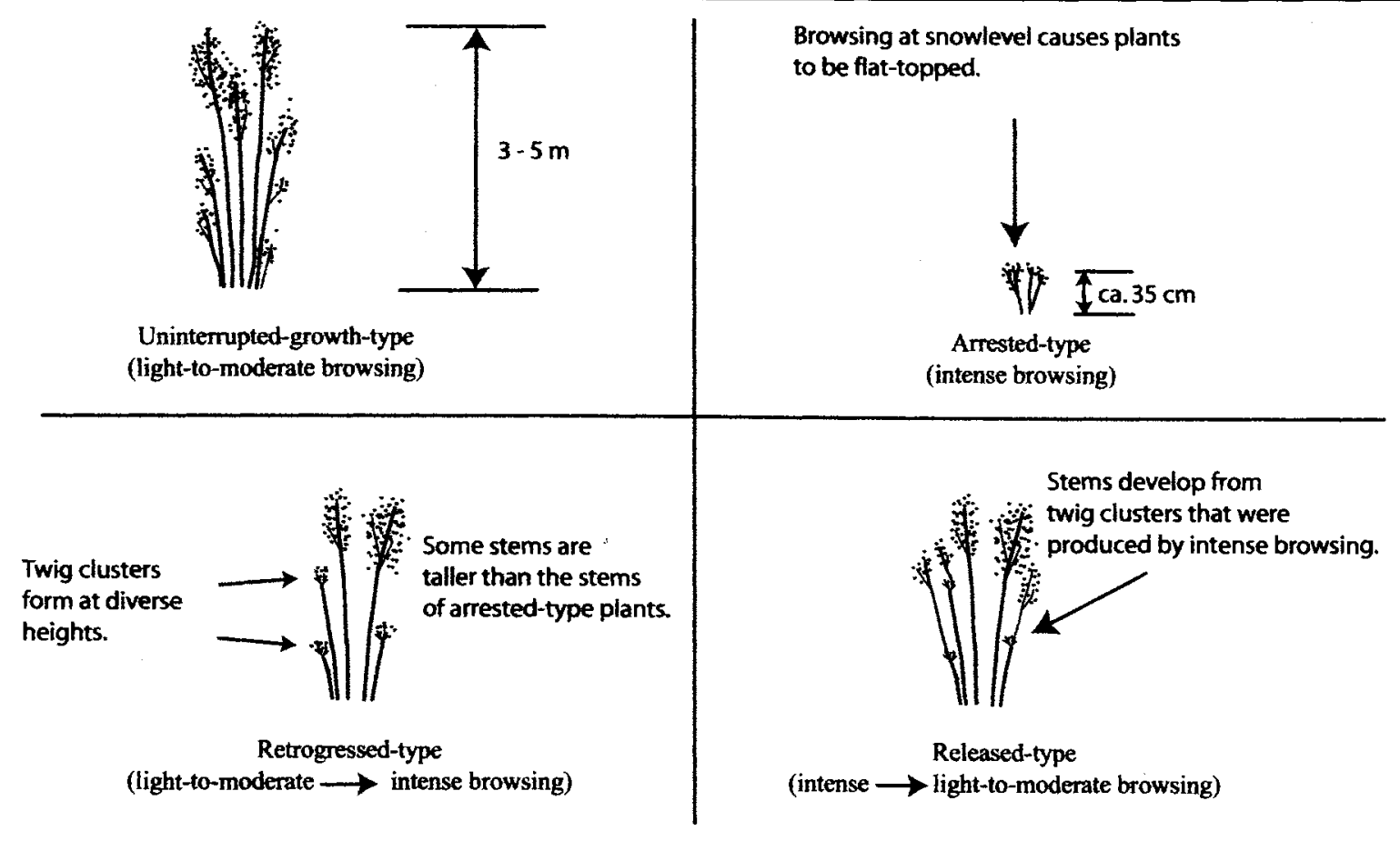

Fig. 6. Browsing-related architectures.

ture-types that correspond to four browsing regimes (Fig. 6 ). The architectures are produced during the period of time that the terminal leader grows within the browse zone. They are:

a) Uninterrupted-growth-type architecture (produced under light-to-moderate browsing conditions),

b) Arrested-type architecture (produced by intense browsing),

c) Retrogressed-type archtecture (produced by a change from light-to-moderate browsing to intense browsing), and

d) Released-type architecture (produced by a change from intense browsing to light-to-moderate browsing).

Because these architectures are mainly produced when the plant is young, one can interpret the browsing history of a site by examining plants of different age.

To assess trend, we examined the architecture of plants with terminal leaders in the browse zone. At Mt. Haggin,

\section{Measurment Units}

Our methods involve relationships between small lengths (stem growth rates that are sometimes less than one inch per year) and large lengths (plant heights greater than 8 feet). Because calculations involving inches and feet are cumbersome, field measurements were made in metric units.

Throughout the text, length measurements are described in English units, with values often rounded to the nearest inch or foot. The measured metric units are presented in parentheses. the browse zone extends from a lower limit of about 8 inches $(20 \mathrm{~cm})$ above ground level to an upper limit of about 8 feet $(2.5 \mathrm{~m})$. Plants are apparently browsed at 8 inches early in the winter season as snow begins to accumulate. The upper limit of the browse zone is controlled by ungulate reach. Stems greater than about 5 feet $(1.5 \mathrm{~m})$ may be out of direct reach of deer and livestock; elk and moose can reach upwards of 8 feet $(2.5 \mathrm{~m})$. Browsing at heights greater than those upper limits can occur when ungulates stand on crusted snow, stand on hind legs, or bend stems to the ground.

We characterized the level of browsing by examining the architecture of plants in which the base of the terminal leader was between 30 and 60 inches $(75-150 \mathrm{~cm})$ tall. Plants in this height range likely were exposed to browsing during recent winters.

We distinguished between two situations: a) all plants exposed to browsing have arrested- or retrogressed-type architecture (mapping unit: "100\% intensely browsed"), and b) some plants exposed to browsing have uninterrupted-growthor released-type architecture (mapping unit: " $<100 \%$ intensely browsed"). In the case where all plants have arrested- or retrogressed-type architecture, it is probable that no young plants will attain their potential height. In the second case, some plants apparently will attain full stature, and the desired condition will be maintained or attained.

As we traversed the field survey area, we delineated the willow area on an aerial photograph. We partitioned that area into the two mapping units described above. As we moved through an area, we sought out plants that might have uninterrupted-growth- or released-type architecture. 
When such plants were found, we tried to determine why they had escaped browsing. If a plant was deemed to have escaped browsing because of local protection, we discounted the architecture of that plant as an indicator of area-wide browsing pressure. Local protection of a young plant might occur when a taller neighbor inhibits ungulate access, either directly or by creating a deep snowdrift. When these circumstances were confined to a few square meters, we assumed that the protective effect was temporary.

Plant height. Plant height was documented by narrative description in the Sullivan Creek survey and by mapping in the Deep Creek survey. In the Sullivan Creek survey, we described the general circumstances under which willows greater than 10 -feet $(3-\mathrm{m})$ tall were found.

In the Deep Creek survey, we distinguished between three plant-height categories: a) Short (the plant is $<20$-inches $(50-\mathrm{cm})$ tall, symbolized by "S"), b) Intermediate (between 20 -inches $(50-\mathrm{cm})$ and 9.8 -feet $(3-\mathrm{m})$ tall, symbolized by "I"), and Tall (>9.8-feet (3-m tall), symbolized by "T"). Plant-community height characteristics were described using combinations of the three categories: S, I, T, SI, ST, IT, and SIT. For example, a community composed of willows less than 20 -inches $(50-\mathrm{cm})$ tall and willows greater than 9.8 -feet $(3-\mathrm{m})$ tall would be designated ST. A site that has experienced protracted intense browsing may be composed entirely of plants in the S category. During the winter, plants in the S category often are buried by snow and unavailable to ungulates. Plants in the $\mathrm{I}$ and $\mathrm{T}$ categories are a source of browse under diverse snow cover conditions.

Category $\mathrm{T}$ was distinguished because stems greater than $3-m$ tall often escape browsing. The presence of tall terminal leaders might allow a shrub to persist longer than shrubs that solely consist of shorter terminal leaders that are all heavily browsed. As in the mapping of browsing level, the total willow area was delineated on an aerial photograph and partitioned-as we traveled across the areainto the 7 mapping units listed above.

Deep Creek field survey. The surveyed segment was about 0.6 miles $(1 \mathrm{~km})$ long; willow covered 270 acres (110 ha) (Fig. 7). The entire area was classified as $100 \%$ intensely browsed. As above, the few uninterrupted-growth type plants were growing in vicinity of taller, heavily browsed, neighbors. We assumed the mechanical protection was temporary.

Stands that included willows greater than 9.8 -feet $(3-\mathrm{m})$ tall constituted $33 \%$ of the total willow area of 89 acres $(36$ ha) (Fig. 8). The remainder of the area (i.e., 67\%) consisted of willows that ranged in height from ca. 8 inches to 8 feet $(20-250 \mathrm{~cm})$ tall. While we currently have no basis for quantitatively predicting the rate of decline, we do know that $67 \%$ of the willow area is susceptible to a relatively rapid rate of decline.

Sullivan Creek field survey. The surveyed segment of Sullivan Creek was about 2.2 miles $(3.5 \mathrm{~km})$ long; willow

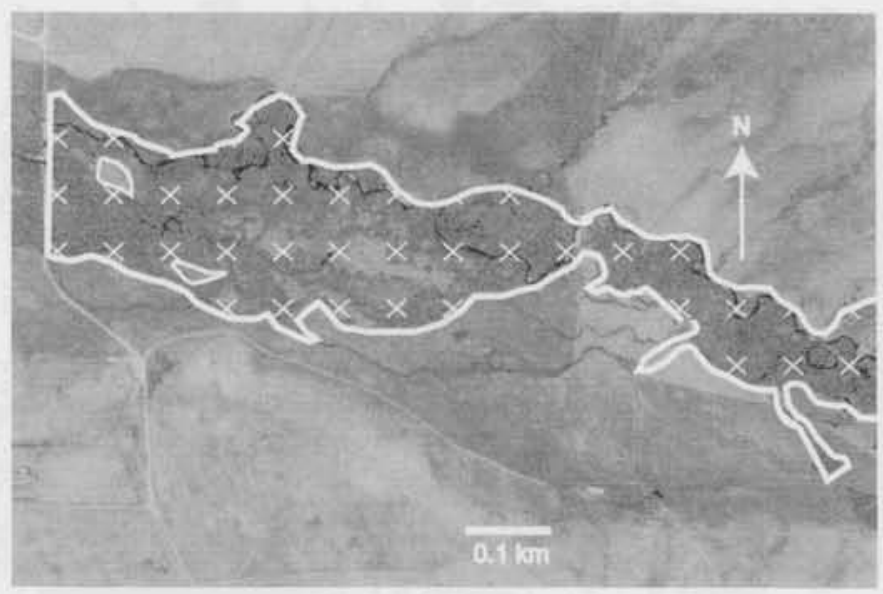

$\times \times \times$ All plants intensely browsed

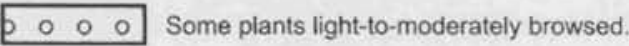

Fig. 7. Browsing intensity on Deep Creek segment of field survey. The entire area was $100 \%$ intensely browsed.

covered 570 acres (230 ha) (Fig. 9). The entire area was classified as $100 \%$ intensely browsed. Uninterruptedgrowth-type plants were uncommon. In each case, we could identify how the plant was mechanically protected from browsing. If current browsing pressure continues, the protection will be temporary. As the plants adjacent to the uninterrupted-growth-type plants die, moose will focus on the remaining live plants.

Willows greater than 9.8 feet $(3 \mathrm{~m})$ tall grow in linear zones along current and relict watercourses. Linear zones of tall willows are also associated with beaver dams. Many of the ponds have drained, allowing willows to become established there; these willows range in height from about 8 inches to 7 feet $(20-200 \mathrm{~cm})$ tall. Willows could have become established on the beaver dams when the ponds were still filled with water, so in part, willows growing on the dams may be taller because they are older than willows growing on the former pond areas. In part, the difference in

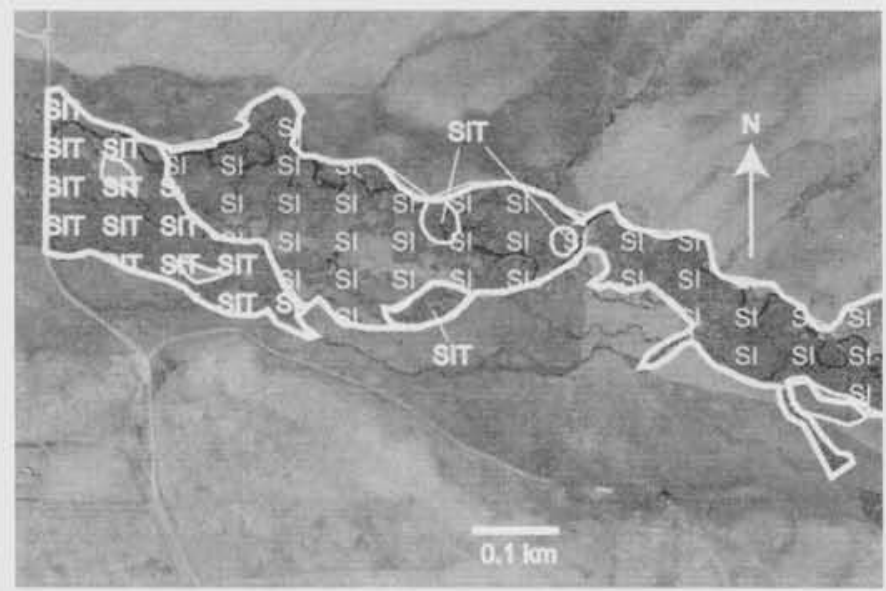

Fig. 8. Willow height at Deep Creek segment. 

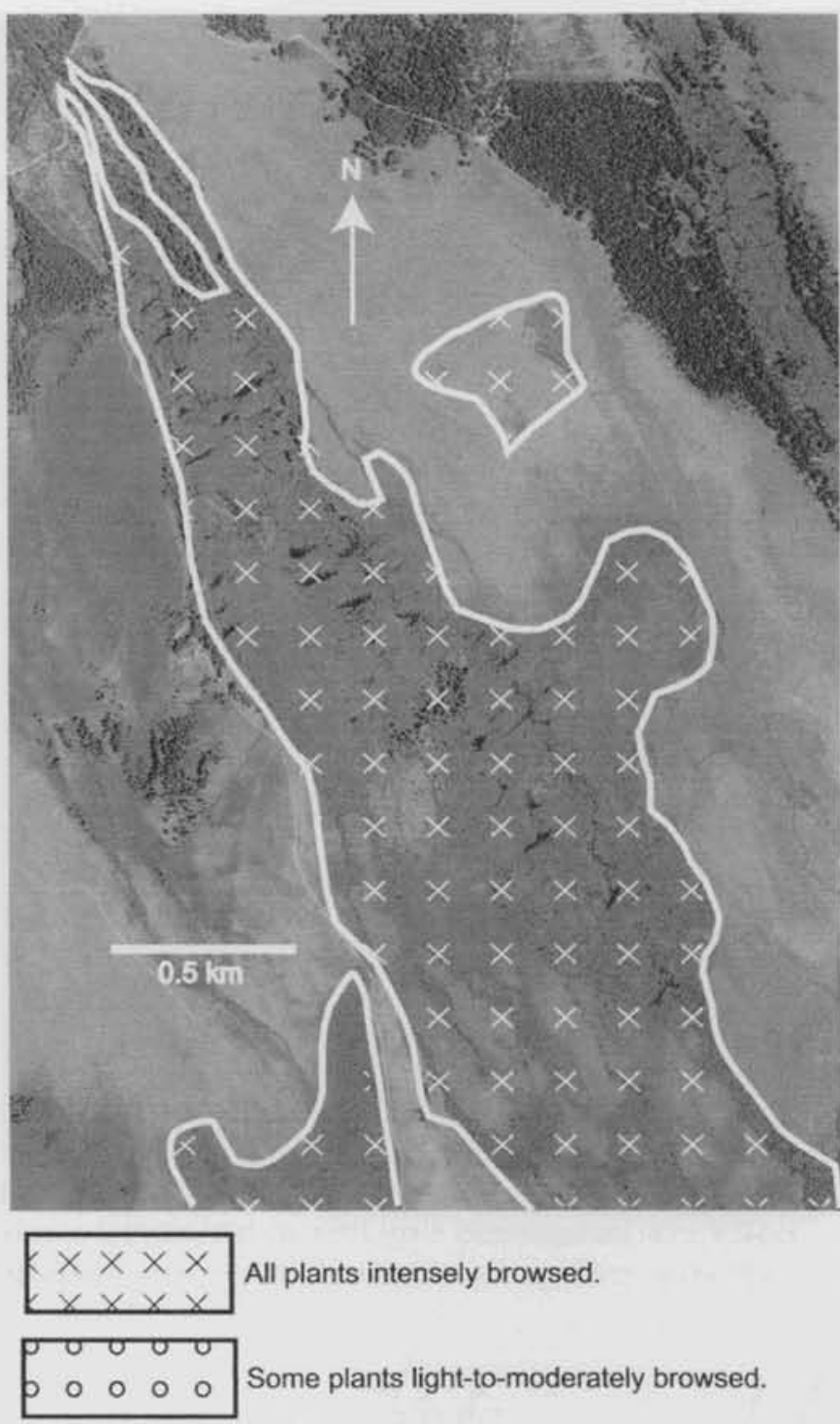

Fig. 9. Browsing intensity on Sullivan Creek segment of field survey. The entire area was $100 \%$ intensely browsed.

height might be due to heavier browsing of willows growing in the pond areas. A dendrochronologic analysis of stems indicates that browsing pressure increased in the mid-1980s. Willows established since the 1980s would have experienced intense browsing while the tallest terminal leaders were within the browse zone. There is extensive mortality of shorter willows.

\section{Summary of Part 1}

We described above how plant architectures can be used to assess browse trend across large geographic areas. However, the statistical analysis of the architecture data is limited. In Part 2 of this paper we describe how browse trend was further assessed using quantitative data that were periodically collected at fixed sites. We refer to that phase of trend assessment as "monitoring."
About the authors: Richard B. Keigley, Ecologist, U. S. Geological Survey, Biological Resources Division, 632 Coulee Drive, Bozeman, MT 59718. Michael R. Frisina, Range Coordinator, Montana Fish, Wildlife, \& Parks, Butte, MT, 59701-2112. Craig W. Fager, Wildlife Biologist, Montana Fish, Wildlife \& Parks, 1820 Meadowlark Lane, Butte, MT, 59701

Acknowledgements: The study was funded by Montana Fish Wildlife\& Parks and by the United States Geological Survey. This paper was peer reviewed. The authors thank Dick Jachowski, Steve Knapp and Kriss Douglass for reviewing an early draft, and thank an anonymous reviewer.

\section{References}

Aldous, C.M. 1945. A winter study of mule deer in Nevada. J. of Wildlife Manage. 9:145-151.

Dasmann, W.P. 1951. Some deer range survey methods. California Fish and Game. 37:43-52.

Frisina, M. R. 1992. Elk habitat use within a rest-rotation grazing system. Rangelands 14(2):93-96.

Julander, O. 1937. Utilization of browse by wildlife. Transactions $2^{\text {nd }}$ North American Wildlife Conference. pp. 277-285.

Keigley, R.B. 1997a. A growth form method for describing browse condition. Rangelands. 19:26-29.

Keigley, R.B. 1997b.. An increase in herbivory of cottonwood in Yellowstone National Park. Northwest Science. 71:127-136.

Keigley, R.B. 1998. Architecture of cottonwood as an index of browsing history in Yellowstone. Intermountain Journal of Sciences. 4:57-67.

Keigley, R.B. and M. R. Frisina 1998. Browse evaluation by analysis of growth form. Montana Fish Wildlife \& Parks. 153 pp.

Nelson, E.W. 1930. Methods of studying shrubby plants in relation to grazing. Ecology. 11:764-767.

Stickney, P.F. 1966. Browse utilization based on percentage of twigs browsed. J. of Wildlife Manage. 27:76-78. 